\title{
ECONOMÍA LIBIDINAL Y SUBJETIVACIÓN. TRAMA Y DES- ENLACE DE LA CONSTITUCIÓN SOCIOPOLÍTICA EN FREUD
}

\author{
Francisco Vega C. ${ }^{1}$ \\ Pontificia Universidad Católica de Valparaíso
}

\begin{abstract}
Resumen: En este trabajo se intentarán bosquejar algunas consecuencias éticas y políticas fundamentales que aportaría el psicoanálisis. Para ello hemos recorrido un trayecto por algunos textos freudianos, gravitando de forma preferente en sus textos antropológicos y sociopolíticos. Luego de explanar de forma sucinta lo que Freud entenderá por economía libidinal, avanzaremos hipótesis sobre las relaciones de la formación psíquica con el proceso cultural, esto es, sobre la producción de subjetividad y su relación con los vínculos intersubjetivos, para luego abrir y analizar desde esa plataforma algunas tesis sobre el sujeto y el estatuto de lo político en Freud.
\end{abstract}

Palabras clave: pulsión, economía libidinal, sujeto, cultura

\section{Libidinal e conomy and su bjectivity. Plot an d de-link o f the socio-political constitution in Freud}

Abstract: This paper attempts to outline some fundamental ethical and political consequences that psychoanalysis would bring. For this we've gone through some Freudian texts, gravitating preferentially around his socio-political and anthropological texts. After grading succinctly what Freud understands as libidinal economy, it will be advanced an hypotheses about the relationships between mental formation and the cultural process, namely about the production of subjectivity and its relation with the intersubjective links. Afterwards we analyze, from there, some theses on the subject and the status of politics in Freud.

Keywords: drive, Libidinal economy, subject, culture

\section{INTRODUCCION}

El trayecto que queremos recorrer para constituir una plataforma sólida de análisis, que nos permita desentrañar el estudio de lo político efectuado por Freud, está establecido alrededor de unos términos claves bien delimitados. Se trata de los conceptos de pulsión, economía libidinal y cultura. Articulando estos conceptos medulares lograríamos profundizar ya el núcleo teórico que moviliza la tentativa freudiana. Desde ahí, en su detalle más o menos exhaustivo, deberíamos determinar el estatuto que tendrían en Freud los conceptos de verdad e historia, en la medida en que parecen constituir la égida de las críticas y análisis mayormente efectuadas con y contra el psicoanálisis, desde las primeras investigaciones freudomarxistas y de la Escuela de Frankfurt hasta los análisis

\footnotetext{
${ }^{1}$ Magíster @ en Filosofía, Pontificia Universidad Católica de Valparaíso, Chile.
} 
efectuados desde el estructuralismo y la (mal) denominada corriente postestructuralista ${ }^{2}$.

La idea entonces es delimitar o bosquejar una teoría de la subjetividad en Freud, donde se hará necesario detenerse perspectivamente en la importancia y en el estatuto que tiene la pulsión de muerte, para analizar cómo esa subjetividad así mentada se inserta en un plexo de relaciones sociales. Para alcanzar no obstante una suficiente claridad respecto a la estructura individuo-cultura, se hará necesario por su parte atravesar brevemente la genealogía histórica que emprende Freud, pues está íntimamente vinculada en su problematización. Con el desarrollo de estos elementos (sujeto, cultura, historia) se obtiene un cruce entre el análisis filogenético emprendido por Freud y el análisis ontogenético, en cuyo seno habrá al parecer que inscribir la problemática de la cultura.

Con el des-pliegue de estos motivos se hace necesario esbozar algunas preguntas directrices, todas ellas relacionadas. Por una parte, podría verse en el mismo Freud toda una sintomatología postromántica, que prueban las múltiples y sabidas referencias a Schopenhauer, a Schelling, como la muda pero constante referencia a Nietzsche, con las cuales se consumaría un pensamiento dicotómico naturalista que albergaría la idea de un sujeto anterior a toda formación cultural, o sólo modulado por el proceso cultural. Esta hipótesis se desarrollaría a pesar de entender a Freud como uno de aquellas heridas modernas (junto con Marx y Nietzsche según el célebre dictum de Foucault) que desbaratarían la confianza en la autonomía de la subjetividad y la transparencia de sus representaciones. A pesar de esta idea, como señalamos, pareciera verse en el psicoanálisis freudiano una substancialización subjetiva y un desligamiento de las estructuras sociales, desde el momento en que se reducen a Edipo los vínculos intersubjetivos y, con ello, se hace gravitar en el sexo (pansexualismo muy consabido y comentado) el desarrollo cultural.

No pretendemos dar cabida a un análisis de este tipo, revelado de inmediato como interminable, pero por lo menos abriremos sus premisas destacadas y ensayaremos una lectura de Freud que posicionaría la concepción heterónoma de los desgarros modernos de una forma modulada respecto a las concepciones políticas clásicas, incluido Hobbes.

\section{La máquina anímica: pulsión de muerte y economía libidinal}

Para allanar entonces el camino que nos proponemos convendría destacar desde ya las premisas germinales que harán a Freud establecer su concepción de la cultura y del sujeto político. Pues bien, para el desarrollo en psicoanálisis de una ontología del ser-político o del ser-en-común, debemos tomar como marco conceptual no otra cosa que el despliegue de la economía libidinal freudiana,

\footnotetext{
${ }^{2}$ El término postestructuralismo fue preferentemente usado en departamentos no filosóficos para englobar autores que emprenden tentativas diferentes. Queda muy claro esto respecto al psicoanálisis, ya que si bien cabe hacer analogías, habrá que ser muy cuidadoso al momento de analizar respectivamente las posiciones de Deleuze, Guattari, Foucault y Derrida en lo que a psicoanálisis se refiere.
} 
donde se hará patente la importancia que cobra el desarrollo analítico de la pulsión de muerte.

Se ha destacado la relación que guardaría Más allá del principio de placer de 1920 , donde se somete a inspección de forma inaugural el tema de la pulsión de muerte, con el primigenio Proyecto de una psicología para neurólogos de $1895^{3}$. Pues en éste se puede apreciar, bajo un ímpetu mecanicista que sentaba las bases de una Naturewissenchaft y, con ello, de la visión cuantitativa del análisis freudiano, un esquema mental (o máquina mental) estructurado en tres ejes fundamentales que, como se sabe, serán los estímulos, la descarga y la recarga y que gravitan en torno al "principio de inercia neuronal", es decir, la tendencia del aparato anímico a mantener lo más bajo posible los montos de excitación o, a lo menos, a mantener constante la tensión interna, en cuanto será el desajuste de dichas cantidades, o tensión interna, lo que produzca las alteraciones mentales.

Si bien bajo los influjos de esa Naturewissenchaft, es el sistema estructural del aparato anímico junto con los procesos primarios lo que interesa a Freud, vale decir, lo que interesa ya es no tanto el análisis biológico de la mecánica mental sino su vida anímica. Esta breve mención sirve para contextualizar el aporte de Freud e introducir la economía libidinal que nos interesa y que tomará contrastes más claros con el análisis del principio de placer y la pulsión de muerte. Pues de este primer sistema estructural mecánico dimanará una teoría del sujeto cuyo fundamento será el despliegue de la especulación psicoanalítica de la pulsión de muerte. Así, para que la modulación con respecto al Proyecto quede clara, y para que despejemos nuestro camino, describamos de forma sucinta esta especulación.

Para Freud el proceso primario tiende al placer, evitando estímulos o descargando para así equilibrar la tensión interna (se verá que la inercia se relaciona con el proceso primario). Esta misma lógica barrunta el comienzo de Más allá del principio de placer cuando se señala que el decurso de los procesos anímicos es regulado por el principio de placer ${ }^{4}$. Estamos así en el plano de la homeostasis del organismo. Freud hablará entonces de las rupturas de este gobierno del placer (gobierno en cuanto es principial y no objetivo o telos) aunque no contradigan su imperio. Es con las neurosis traumáticas y con el análisis del juego infantil de su nieto Ernest que se va haciendo patente la idea de una compulsión a la repetición que tomará ya el carácter de pulsión tras el análisis de las neurosis de transferencia, pues preliminarmente, en el análisis del juego de su nieto, por ejemplo, Freud habría señalado que toda repetición de una escena desagradable iba conectada al fin con una ganancia de placer, pero "placer de otra índole". Este tipo de repetición mienta lo que Freud establecerá a su vez luego, esto es, que la repetición de lo reprimido inconsciente produce displacer al yo, pero esta clase de displacer es reconocido como placer para otro sistema, el inconsciente.

\footnotetext{
${ }^{3}$ Cfr. James Strachey, "Introducción" a Más allá del principio de placer. Las citas de Freud se hacen de acuerdo a la edición de Amorrortu Editores (Sigmund Freud, Obras Completas, Bs. As., 2003). Estas citas se identificarán sólo mediante el nombre del texto, la sigla $A E$, el número del volumen y la página.

${ }^{4}$ Cfr. S. Freud, Más allá del principio de placer, AE, t. 18, p. 7.
} 
Freud al final concreta su análisis preliminar con la compulsión a la repetición, puesto que se hace patente en ella el hecho de vincular escenas que no contienen posibilidad alguna de placer, ni siquiera de lo pulsional reprimido. Así, siguiendo el análisis freudiano de los obstáculos aparentes del gobierno del principio de placer, se asociará a la repetición los rasgos de un placer maldito, en oposición a ese primer estado del placer asociado a la homeostasis del organismo, y maldito en la medida en que se resiste a ser regulado. En un primer momento entonces, siguiendo ese placer de sensación ligado a la homeostasis, se puede afirmar que el sujeto es producido por el placer, comanda su accionar. Esta producción es modulada por Freud cuando ese placer va tomando en el análisis los rasgos malditos que dimanan de lo que inmediatamente Freud establecerá como pulsión de muerte, entendida como una instancia que inexorablemente arrastra al sujeto a una escena anterior, mítica, y que desapropia al sujeto.

Si bien en 1895 Freud habla de principio de constancia y ahora, en 1920, habla de principio de placer, lo que tiene en mente son, como dijimos, los procesos primarios ligados al aparato anímico. El paso decisivo se establece con la institución de la subjetividad. Y es que su introducción establecerá, como señalamos, una primera ruptura con el plano del organismo. De la satisfacción de la necesidad, en el plano homeostático del organismo, donde converge el organismo con el medio, se pasa a la realización de deseo, en el plano ya del sujeto, que bajo el marco de la identidad de percepción alucinatorio cumplido en el sueño, constituye al objeto del deseo como objeto perdido. Esta realización de deseo, aún sin hablar de la pulsión de muerte, está marcada por la repetición y constituye la modulación, bajo la institución del principio de realidad, de la primera economía libidinal del organismo. Se trata de la Spaltung freudiana, y que Lacan entenderá como el arranque desdichado de la subjetividad.

Tenemos así un primer placer homeostático en el plano de la satisfacción de necesidades y otro plano que constituye ese placer en un placer de desear, de desear el objeto perdido de la primera satisfacción o escena mítica, y que será un placer no obstante displacentero para el yo. Se puede entonces entender el proceso primario, cosa que liga los textos que analizamos, como una defensa frente a la irrupción del goce antihomeostático que no puede impedir la emergencia de lo no ligado ${ }^{5}$. Queda así ya claro como se trata de una nueva economía del organismo-sujeto con lo real que modula la primera.

Esta escena traumática no tiene otro sentido que economía y recuérdese que para Lacan el trauma es la existencia misma del sujeto al atravesar el campo simbólico, presente ya en Freud en el análisis del Fort -Da. Es la emergencia del sujeto que señala un corte con el organismo en su economía con lo real. Pues si en un primer instante el organismo tenía hambre, ahora el sujeto tiene "hambre de signos"6.

Con todo, Freud nos mostrará, avanzando en el texto de Más allá.., que existe en la repetición la evocación no sólo de deseos inconscientes sino también

\footnotetext{
${ }^{5}$ Cfr. Juan Carlos Cosentino, "Capítulo I de Más allá del principio de placer" en: Puntuaciones freudianas de Lacan: Acerca de Más allá del principio de placer, J. C. Cosentino y D. Rabinovich (comp.), Bs. As.: Manantial, 1992, p. 23.

${ }^{6}$ Ibíd., p. 14.
} 
experiencias que en su momento no pudieron traer consigo cuota alguna de placer. Habrá entonces otra ruptura, que sólo modulará la anterior pues no es un quiebre de su sistema ya que están encadenadas, y que se refiere al dolor del exterior y que se articula con el sentimiento doloroso del renunciamiento de la vida pulsional. Poco a poco así vamos llegando a lo que constituirá el establecimiento de la pulsión de muerte, que en base a estas consideraciones parece dislocar todo programa sociocultural.

El resultado es al final un sujeto que de la primera caracterización homeostática del placer es fracturado por la pulsión de muerte y compelido a repetir esa escena mítica primigenia que desapropia al sujeto, en la medida en que mientras más se apropia del placer en busca de la descarga de excitación, más se desapropia, pues al fin del trayecto está la muerte, y el camino hacia ella propio de cada organismo. $Y$ sujeto escindido, podemos señalar, al ser ambas pulsiones, la pulsión de muerte y las pulsiones yoicas, detalladas por Freud como complementarias ${ }^{7}$.

En resumen, en un primer momento, Freud (bajo la influencia mecanicista de Fechner) afirmará que es el principio de placer quien regula el aparato anímico. Lo pondrá en marcha entonces una tensión interna cuya orientación será la evitación del displacer o la producción del placer, entendiendo con estos términos la cantidad de excitación del aparato anímico, gravitando así el principio de inercia como tendencia a la estabilidad. Freud se detendrá entonces a analizar aquellas experiencias que parecen destronar el imperio del placer. En el análisis del catálogo de estas experiencias la neurosis mostrará a Freud que aquello que el analizante repite se opone al principio de placer y revelará al fin, luego de las rupturas analizadas, el establecimiento de la pulsión de muerte.

En la Traumdeutung Freud establecerá por su parte una distinción entre satisfacción de necesidad y realización de deseo que hemos ya mencionado. Esto nos revela que la satisfacción de necesidad tiene relación con la homeostasis del organismo y que la realización de deseo se relaciona con el sujeto ya estructurado como sujeto del inconsciente, donde todo objeto del deseo se transforma en objeto perdido. El placer, ya alejado del esquema homeostático del organismo, dimana placer de desear, siendo inevitable y tomando con ello los rasgos malditos que mencionábamos.

Al final, lo que obtenemos es una ontogénesis delimitada entre estas dos pulsiones. Por una parte el sujeto estaría estructurado por la pulsión de muerte, que impele la vuelta hacia un estado anterior, inanimado, y que funciona por proceso primario. Por otra parte, las pulsiones de autoconservación, que tienden hacia la vida y el progreso, lo animado, y que funcionan por proceso secundario.

Podría entenderse que Lacan es a Freud lo que Derrida es a Heidegger, pues es en la estela de sus premisas, sumando los aportes de la lingüística estructural, de donde establecen sus tentativas teóricas. Como es sabido, para Lacan habría un sujeto del enunciado y un sujeto de la enunciación (de ahí el sujeto barrado) pues el sujeto se configura al límite entre un texto consciente y otro texto inconsciente,

${ }^{7}$ Cfr. S. Freud, Más allá del principio de placer, op. cit., p. 55. 
lo que articula el límite de todo discurso ${ }^{8}$. El significante para Lacan es también un puro diferimiento, cuestión que articula nuevamente esa desapropiación subjetiva que mienta al fin la pulsión de muerte, en la medida en que el sujeto se define por su concatenación significante. Si para Freud lo más propio, lo intimo, constituía también lo más impropio, la desapropiación absoluta dada la pulsión de muerte, lo extimo, para Lacan esa extimidad estará dada por la estructura significante. Extimidad que nadie ha capitalizado mejor que el yo es otro de Rimbaud, en los márgenes del racionalismo cartesiano que no cesa de mencionar Lacan como bisagra epocal abierta por Freud. Recuérdese que la pulsión de muerte destruye toda principialidad y toda edificación, toda sujeción, de ahí su carácter demoníaco que más tarde analizaremos ${ }^{9}$. El trayecto da paso así a lo que podemos llamar entonces una economía de la muerte, una tanatografía que traerá importantes consecuencias en el plano social.

Lo que debemos destacar es lo siguiente. Freud analiza en los primeros capítulos de Más allá... el aparato anímico en su relación con lo real, que establece una primera economía que será luego reestructurada con la institución del principio de realidad y el proceso cultural asentado en la filogénesis, cosa que veremos. En ese trayecto, lo que quedará del análisis de esta economía libidinal será el reconocimiento de ese rasgo maldito que es el principal aporte de Freud.

Conviene destacar entonces cómo Freud señala en Más allá... que las pulsiones de conservación son pulsiones parciales destinadas a asegurar el camino hacia la muerte propia de cada organismo ${ }^{10}$. Acá se hace evidente este carácter maldito que sitúa a la muerte más allá del imperio del placer. Lo que nos debe interesar así es que un poco más adelante Freud señala refiriéndose a la existencia de una pulsión de perfeccionamiento:

“(...) yo no creo en una pulsión interior de esa índole, y no veo ningún camino que permitirías preservar esa consoladora ilusión. (...) el infatigable esfuerzo que se observa en una minoría de individuos humanos hacia un mayor perfeccionamiento puede comprenderse sin violencia como resultado de la represión de las pulsiones" 11 .

Al final, como se sabe, para no echar por la borda una hipótesis tan poco agradable como la de la pulsión de muerte, Freud mostrará la necesidad de hacer complementarias la pulsión de muerte con las pulsiones de vida, obteniendo con ello una lógica diferencial que parece ir más allá, pese a las apariencias, de las concepciones políticas clásicas como la de Hobbes, de forma destacada en la

\footnotetext{
${ }^{8}$ Cfr. J. Lacan, "La cosa freudiana o sentido del retorno a Freud en psicoanálisis" en: Escritos 1, México: Siglo XXI, 1990, p. 395. Al igual que Derrida, Lacan habla ahí del límite místico de todo discurso.

${ }^{9}$ Cfr. S. Freud, Lo ominoso, AE, t. 17. Ahí lo siniestro es determinado como el retorno de lo reprimido inconsciente que se creía superado, asociado acá a la pulsión de muerte.

${ }^{10}$ Cfr. S. Freud, Más allá..., op. cit., p. 39.

${ }^{11}$ S. Freud, Más allá..., op. cit., p. 41. Consignada en nota en la misma página J. Strachey señala que Freud utiliza para el término refuerzo el alemán Triebverdrängung, cuando antes ya había ocupado Drängen para describir el esfuerzo de fuerzas externas que empujan la adaptación. Así, entre adaptación y refuerzo cultural parece configurarse el problema.
} 
medida en que aparecen importantes analogías ${ }^{12}$. Pues podríamos entender que tanto los paradigmas antiguos, aferrados a la idea de naturalizar lo vínculos intersubjetivos y el paradigma moderno, ya sea en clave roussoniana o hobbesiana, aferrado a la idea contraria de desnaturalizar esos vínculos, tienen de común el substantivizar la ligazón o el enlace sociopolítico, ya sea por la necesidad del otro, por el amor o fraternidad (que para Freud sería sólo amor de meta inhibida) o por el temor o terror mutuo.

Freud aúna ambas concepciones al instalar la necesidad (Ananké) como pilar junto con Tánatos, generando con ello un paradigma específico que toma toda su fuerza en el establecimiento de una des-substancialización de los vínculos y en una vigilancia sobre las ligaduras contingentes efectuadas por la cultura ${ }^{13}$.

Digamos para avanzar que el modelamiento de la primigenia economía libidinal se configura luego con las exigencias forzadas de la necesidad y luego con las exigencias reforzadas de la cultura. Así el sujeto entra en una relación económicodinámica con la técnica, cuestión que contradice la tesis de Marcuse, al problematizar sólo las instancias represivas que, si bien son destacadas por Freud, entran en conjunto con otras relaciones de producción más complejas y vinculadas, y que a su vez hacen problemática la noción de utopía ${ }^{14}$.

Lo que nos queda detallar entonces serán las consecuencias de la pulsión de muerte y el sentimiento doloroso de la renuncia pulsional cuando entra en juego la cultura y su historia filogenética: ¿Qué pasa con ese sujeto económico del placer que no puede frenar esos rasgos demoníacos inherentes cuando se entra en juego con el plexo social y las instituciones? ${ }^{15}$

\section{La máquina cultural: origen de la civilización y enlace sociocultural}

En el primer capítulo de El malestar en la cultura de 1930 Freud nos señala que en la vida anímica nada se pierde y que la conservación del pasado es su regla, en cuanto no hay aniquilación de la huella mnémica, cuestión que prueba todo ejercicio analítico. La imposibilidad de ver en la actual arquitectura de Roma todo el legado de su arcaica y hermosa constitución arquitectónica hace decir a Freud cuán lejos estamos de dominar la vida psíquica mediante figuraciones. Esta fabulación freudiana debería alertarnos para abordar desde ya el estudio que Freud esboza sobre los orígenes de la civilización, puesto que volveremos a encontrar ahí implicadas el conjunto de tesis que poblarán el análisis del problema de la subjetivación, entendiendo por tal la constitución de un sujeto en una cultura política determinada o la producción de subjetividad de un régimen cultural.

\footnotetext{
${ }^{12}$ Destacadas por el mismo Freud en El malestar en la cultura, AE, t. 21, p. 108.

${ }^{13}$ Cfr. Myriam Revault d'Allones, "Pulsiones de muerte e intratable socialidad" en: La pulsión de muerte: Entre psicoanálisis y filosofía, Bs. As.: Nueva Visión, 2006, p. 39.

${ }^{14}$ Lo mismo señaló Foucault al tipo de análisis de Marcuse. Cfr. M. Foucault, Microfísica del poder, Madrid: Ed. La Piqueta, 1992, p. 108. ¿No será mejor hablar con Freud de dislocación o atopía? Sobre esto volveremos más adelante.

${ }^{15}$ Bertrand Ogilvie de forma muy elocuente y cercana a lo que intentamos precisar acá señaló en Psicoanálisis y modernidad (conferencia inédita realizada en Valparaíso):"Sujeto es todo aquello de lo que se preocupan las instituciones".
} 
Teniendo claro este pasaje filogenético obtendremos mayor claridad al enfrentar la economía libidinal, antes estudiada, con las exigencias culturales que luego analizaremos recorriendo de forma destacada El malestar en la cultura.

Freud, como sabemos, someterá a un análisis crítico y vinculante los conceptos de pulsión de muerte, autoridad paterna y represión con la tríada formada por la ética, la sociedad y la religión. Aún cuando señale que la cultura, y con ella la Iglesia y la ética, constituyen procesos que continúan en un nivel más abstracto los problemas formados por la primera tríada, uno podría pensar que se trata de una analogía forzada o incluso de un sistema alegórico. No obstante, esta relación no obedece a una figuración alegórica ya que está sustentada en los estudios genealógicos freudianos, aun cuando se presenten como hipótesis especulativas, pues tienen su asiento en una historia concreta que los articula.

En efecto, Freud tomará para su análisis filogenético el aporte del filántropo y especialista en tótem William Robertson Smith, específicamente sus ideas en torno al banquete totémico ${ }^{16}$. R. Smith cree hallar en el tótem el origen de toda religión, específicamente del banquete totémico, es decir, la muerte y la ingesta del animal sagrado. En el asesinato de este animal Smith encuentra una lógica colectiva, ritual, que permite expiar la culpa por la misma muerte, teniendo así el asesinato la función de reforzar los vínculos sociales. Por otra parte, extraerá Freud de Darwin la idea de horda. Con esta doble base, Freud señalará que en sus orígenes la horda era dominada por una macho dominante que se apropiaba de todas las mujeres, cuyos hijos pasarian a formar la masa. De tal modo, este padre sometía a esa masa a una homosexualidad forzada, elementos que en suma tendrían como efecto el surgimiento de inclinaciones asesinas hacia el padre. Uno de los hijos habría dado muerte al padre y lo relevaría. Al final del camino entonces los hijos matarían al padre y se lo comerían en lo que constituye el banquete de la comunidad fraterna que haría culpables a todos y no a uno solo de sus individuos o miembros.

Con todo, dado el sentimiento ambivalente que se tenía al padre, ya que también daba protección, surgiría la culpa, elemento con que nos toparemos más adelante. Lo destacable es que Freud combate la descripción totémica sociológica (para la cual el tótem representa la adoración de la comunidad) y la nominalista (para la cual el tótem obedece a la constitución nominal de una comunidad) para señalar su desprendimiento de análisis basados en la ratio ${ }^{17}$. Al señalar que en el Edipo tendría su basamento el totemismo y la exogamia. Freud intenta justificar toda la ontogénesis desde la filogénesis. Luego del crimen primordial la opción habría sido volverse uno o reivindicar lo uno, la plataforma de la máquina cultural que analizaremos.

La idea fundamental del totemismo sería así, descartadas las teorías sociológicas y nominalistas sobre el tema, la emergencia del crimen original del padre y, con ello, del sentimiento de culpa que dimana de él, y que sería la base germinal del

\footnotetext{
${ }_{17}^{16}$ Cfr. S. Freud, Tótem y tabú, AE, t. 13, p. 135.

17 De forma análoga a lo efectuado en El porvenir de una ilusión con las representaciones religiosas. Cfr. S. Freud, El porvenir de una ilusión, AE, t. 21, p. 40.
} 
padre desplazado que será luego el Tótem, ahora venerado. Esto lo sostendrá Freud en la medida en que se aprecia notoriamente que el animal totémico no se puede matar y que las mujeres que tienen el mismo linaje no se pueden poseer, desde los preceptos del tabú. ¿No se hace siguiendo este análisis ya evidente cómo se conjugan en una comunidad primitiva tanto la religión, ligada al tótem, y los preceptos éticos, ligados al tabú, con los fenómenos de la represión, la tendencia agresiva y la autoridad?

Efectivamente, para Freud de este sustrato germinal dimanará no sólo la religión y la ética sino el conjunto cultural más vasto que podemos llamar el patrimonio de la humanidad. Vemos entonces cómo la historia está inmanentemente conjugada en su totalidad en el análisis de Freud, constituyendo lo que podría ser un análisis, aunque macrológico, de diagnóstico del presente, si seguimos a Foucault, en cuanto esa historia será determinante para la analítica de la modulación económica que Freud observa en la Viena y en la Europa de inicios del siglo XX. Si hemos analizado el devenir-sujeto del organismo y luego mencionado esta filogénesis es para dar cuenta de su íntima vinculación, que quedará más clara en lo que sigue. Lo importante es destacar que se deviene sujeto en una economía con la realidad de acuerdo a sus posibilidades de desarrollo, a sus condiciones materiales y psíquicas, y de acuerdo a disposiciones del organismo humano que hemos desvelado asentadas en la tanatografía. Esta economía del organismo con lo real esta asentada en una historia, la que acá describimos, que a su vez determinará lo que sigue.

Desde otra perspectiva Freud señala que en el bebé operará una impulsión a desasir el yo de la masa de sensaciones, proceso que equivaldría a un primigenio y fundante reconocimiento del afuera, de la realidad. Se constituiría con ello una dicotomía primera entre un yo-placer y un ahí-afuera amenazador, que derivaría en el establecimiento del principio de realidad. La economía libidinal que describimos señalando su génesis estaría conformada por la doble acción que es el evitar el displacer y vivenciar el placer en el establecimiento y transformación del principio de placer en principio de realidad, todo esto en el reconocimiento ya de las amenazas que se oponen al organismo, y que para Freud pueden ser de tres órdenes: la amenaza del cuerpo propio, destinado a su muerte, la amenaza del mundo exterior, azotado por los desastres naturales y la amenaza circundante que suponen los otros ${ }^{18}$.

En esta economía libidinal se ha dado entonces un primer paso que consiste en la constitución del principio de realidad, ya que el gobierno irrestricto del principio de placer fácilmente se revela como peligroso, en la medida en que arrojaría al sujeto a la inseguridad absoluta. Establecido esto el sujeto dispondrá entonces comerciar la ganancia de placer con la evitación del displacer. Esta economía, a su vez, puede dar lugar para Freud a tres formas de resolución: por una parte, la soledad del eremita, aquel que se aleja del mundo para evitar sus amenazas. Por otra parte la dedicación del trabajo, la tarea de aquel que se asigna cambiar el estado de las cosas e intenta dominar la naturaleza. Finalmente puede darse como

18 Cfr. S. Freud, El malestar en la cultura, AE, t. 21, p. 76. 
resolución la intoxicación, es decir la transformación química del cuerpo con el fin de aplacar las amenazas y sus dolores. A estas formas de resolución Freud sumará el amor, el arte y la religión, que constituyen en suma el catálogo de las experiencias que deberían garantizar un equilibrio en la economía libidinal asentada en la cultura ${ }^{19}$.

Detallado entonces este catálogo económico Freud emprenderá la tarea de analizar la genérica hostilidad que observa hacia la cultura. En la genealogía de ésta Freud señalará como aspectos destacables la desvalorización de la vida terrenal efectuada por el cristianismo, el contacto con otras etnias primitivas que mostrarían, en apariencia, una vida menos rígida en comparación con la vida en las metrópolis, y la imposición de reglas de la cual dimana la génesis de las neurosis. Caracteres destacados a los que Freud añade el desengaño respecto a la ciencia, que se creía poder reservar un núcleo de felicidad. No obstante, lo que interesa a Freud es abordar la esencia de la cultura, dirigirse a su constitución germinal para ver allí los elementos que desencadenarían el actual malestar.

Pues bien, relacionado de forma absoluta con las amenazas que ya el infante logra vislumbrar, para Freud la cultura tendría por misión fundamental una doble tarea. Por una parte proteger a los hombres contra los designios y calamidades de la naturaleza y, por otra parte, la regulación de los vínculos intersubjetivos que constituían la tercera forma de amenaza del yo-afuera. Así, Freud establecerá, en consonancia con lo dicho anteriormente, algunos rasgos culturales que conviene destacar. Entenderemos por rasgos culturales, dirá Freud, todas las actividades desarrolladas para poner la tierra al servicio del hombre ${ }^{20}$. A su vez, será constitutivo de la cultura aquello que se opone a lo anterior, en la medida en que valoramos como rasgos destacables de una cultura no sólo lo utilidad de los artefactos sino también, y de forma fundamental, lo inútil, es decir, la belleza que en equilibrio con la utilidad del desarrollo técnico parece hacer verdaderamente valorable un desarrollo cultural. A estos elementos Freud añadirá también el orden y la limpieza, pues difícilmente consideraríamos como notas de la cultura el desorden y la suciedad que, no obstante, son la tendencia natural del hombre para Freud. Por último, y de forma fundamental, habrá que considerar como cultural o propio de la cultura, la regulación intersubjetiva, esto es, la sustitución del poder individual por el poder de la comunidad, cosa que observemos ya estaba prescrita por el tótem y el tabú.

Con todo, lo que se va haciendo patente, sabiendo ya como aducíamos que la satisfacción de las disposiciones pulsionales es la tarea económica de nuestra vida, es que la cultura impone restricciones, cuestión que hace señalar a Freud que la "libertad individual no es patrimonio de la cultura", pues aquel individuo verdaderamente libre lo que haría sería obrar sin considerar esas restricciones y seguiría inexorablemente sus impulsos ${ }^{21}$, cosa que como vimos está fácilmente destinada al fracaso o disolución del organismo. De tal modo, el proceso cultural

\footnotetext{
${ }^{19}$ Ibíd., pp. 80-82.

${ }^{20}$ Ibíd., p. 89. Es destacable que para Freud el mismo fuego ya constituye una adquisición lograda por la renuncia pulsional.

${ }^{21}$ Ibíd., p. 94.
} 
tendría por tarea regular los vínculos intersubjetivos, atendiendo con ello a la economía libidinal, es decir a la satisfacción de las disposiciones pulsionales cuando el individuo entra en contacto con los otros.

En el análisis de este proceso de la cultura (que podemos entender para allanar perspectivamente nuestra tarea como la máquina cultural) Freud detallará las formas que puede adoptar el consumo de las disposiciones pulsionales. Así, por una parte, las pulsiones pueden ser reemplazadas por lo que en un individuo se puede describir como propiedad de carácter, y cuyo caso ejemplar para Freud lo constituye el erotismo anal de los jóvenes, en la medida en que su temprano interés por la función excretora se muda con el tiempo en conductas como el orden y la parsimonia que, en caso de predominar, constituye lo que Freud llama carácter anal. Freud encuentra acá por lo demás una prueba del parecido en que se encuentra el desarrollo cultural con el desarrollo libidinal del individuo ya que, como se había señalado, el orden y la limpieza son rasgos propiamente culturales.

Pues bien, otra forma de consumo de la pulsión puede verse reflejado en cómo muchas pulsiones son movidas a desplazar las condiciones de su satisfacción, cosa que concuerda en la mayoría de los casos, según Freud, con la sublimación de las metas pulsionales y que destaca como rasgo cultural en la medida en que la sublimación permite actividades como la ciencia, el arte y las actividades ideológicas.

Por último Freud aprecia como tercera forma de consumo la asociada a la denegación pulsional, es decir la renuncia o no satisfacción pulsional mediante la represión o sofocación. Este será para Freud, cabe destacarlo, el núcleo más importante e irreductible que constituye el malestar en la cultura, ya que toda pulsión que no sea satisfecha o no compensada va a traer graves consecuencias, como decíamos al comienzo. Lo que a Freud se le impone entonces como égida del problema es según sus palabras lo siguiente:

"Si queremos saber qué valor tiene nuestra concepción del proceso cultural como un proceso particular comparable a la maduración del individuo, es evidente que debemos acometer otro problema, a saber, preguntarnos por los influjos a que debe su origen el desarrollo cultural, por el modo de su génesis y lo que comando su curso"22.

El problema que debería presentarse entonces es aquel que intentamos acá meditar. ¿Cómo es posible hablar de un individuo normal antes de la cultura? Es decir, ¿no encuentra problemas una teoría que afirma el valor normal del individuo soslayando la especificidad de una práctica cultural? Va quedando manifiesto cómo Freud concibe lo que podríamos llamar la maquinación cultural, como un dispositivo que impone a determinados organismos pulsionales sacrificios que nunca hallarán conjunción en una perfecta economía. Pero cabe preguntarse entonces ¿qué estatuto tiene entonces la historia para Freud? Estas preguntas deben ser plantadas más adelante pero encauzadas con aspectos importantes que hemos ganado: a) la concepción freudiana de la economía libidinal del sujeto y su relación con la pulsión de muerte. b) La especulación freudiana sobre el

\footnotetext{
${ }^{22}$ Ibíd., p. 96.
} 
origen de la civilización humana, que nos permitiría comprender mejor c) la maquinaria cultural ${ }^{23}$, sus efectos en el individuo, la génesis de la conciencia moral y su relación con la verdad como su relación con la historia.

Freud volverá a destacar en El malestar en la cultura rasgos que ya había planteado acerca de la unión entre los hombres. Tres cosas son pertinentes mencionar entonces. Freud observa que entre los hombres primitivos se habría dado, considerando la obligación de satisfacer las necesidades naturales, la dicotomía entre considerar al otro como un enemigo o un colaborador. Es fácil apreciar para Freud que el hombre habría elegido la segunda alternativa, ya que la primera conduciría a la inseguridad expuesta de la amenaza del otro ${ }^{24}$. De tal modo, el trabajo surge como el primer elemento a considerar para la génesis de la unión entre los hombres. El segundo elemento, igual de importante, sería la constitución de la familia, efectuada para dar cumplimiento a la satisfacción genital, ya que la demanda del objeto sexual en un escenario no familiar traía consigo el debilitamiento de la satisfacción producto del carácter esporádico que aparejaba.

Expuestas así las cosas puede establecerse el vínculo entre el trabajo y el amor como los pilares germinales de la vinculación humana que habría tenido como primer derecho los preceptos del tabú, tal como Freud lo expone en Tótem y tabú. Así, para Freud son Eros y Ananké los pilares de la cultura. La pregunta que no obstante acecha a Freud es entonces ¿por qué este proceso no aseguro la dicha entre los hombres? ¿Cuál es entonces la fuente de la perturbación? ${ }^{25}$

Freud enseguida se detendrá a analizar un llamado de atención muy común. Muchos, observa, desde un abordaje ético proclaman como ideal de toda cultura el amor. De todos modos, lo que así se hace patente para Freud es la mudanza de la pulsión en una moción de meta inhibida. Actitudes y preceptos como el de amar a toda la humanidad tienen así el carácter de la meta inhibida, cuyo fundamento sigue siendo el amor sensual. Cabría para Freud entonces oponer a esta actitud suprema dos reparos fundamentales, esto es, que aquel amor que no elige comete una injusticia y, por otra parte, que no todos merecen ser amados. De todos modos es evidente que ambos tipos de amor funcionan en la cultura y son su plataforma, ya sea mediante el amor sensual que produce los hijos o el amor de meta inhibida que se exterioriza como ternura y que tiende a hacer alianzas más amplias. Es el desarrollo cultural no obstante el que hará dislocar esta primera vinculación sencilla entre el amor y la cultura.

Y es que, por una parte, el amor contraría a la cultura y ésta la somete a variadas restricciones. Dislocación fundamental que a Freud le parece pertinente destacar en la discordia temprana que se observa entre la familia y la comunidad que la acoge. $\mathrm{Y}$ esto por dos razones importantes. Por una parte, la familia no quiere

\footnotetext{
${ }^{23}$ ¿Es necesario no quitar los rasgos peyorativos del término maquinación? Otro tipo de análisis maquínico debería llevarnos a Deleuze y Guattari, (El Anti-Edipo), cuestión necesariamente desplazada acá.

${ }^{24}$ Cfr. S. Freud, El porvenir de una ilusión, op. cit., p. 15. Se señala ahí que el peligro de la satisfacción total dimana del hecho de que los otros quieren lo mismo.

${ }^{25}$ Cfr. S. Freud, El malestar en la cultura, op. cit., p. 99.
} 
desprenderse del individuo y es patente el sufrimiento que produce esta separación, que se realiza siempre a través de ritos de iniciación en los individuos que se separan, los adolescentes, cuyo dolor Freud extiende de todo desarrollo psíquico a todo desarrollo orgánico. La otra razón a destacar es que la cultura impone variadas tareas a los hombres, los cuales serán movidos a sublimaciones $\mathrm{y}$ al alejamiento de sus funciones de esposo y padre, de suerte que ambas razones harán a las mujeres entran a su vez en discordia con la cultura ${ }^{26}$.

Desde la otra perspectiva es evidente que la cultura somete limitaciones sexuales que ya fueron probadas por Freud en el análisis del totemismo, y que hacen relación también con el hecho de que la cultura impone tareas, o sea un gasto de energía que, por no ser ilimitada en los hombres, debe extraerse de aquellas funciones destinadas a otras cosas. Freud, en una nota digna de mención, señala que la vida sexual de los hombres cultos ha recibido grave daño y que impresiona el retroceso del sexo como función de placer, que parece involucionar como nuestros cabellos y nuestros dientes en su función de órganos ${ }^{27}$.

Además de la satisfacción sexual la cultura para Freud impone otros sacrificios, pero lo importante de destacar es que la dificultad cultural es reconducida a la inercia de la libido, esto es, su renuncia a abandonar una antigua posición, siendo esto lo que constituye su núcleo problemático (y mortífero podemos ya señalar). Perfectamente se puede soñar o imaginar una sociedad de hombres saciados en sí mismos y enlazados por el trabajo, pero es precisamente eso, un ideal que nunca ha acontecido y nunca lo hará, pues la cultura jamás se conforma con las ligazones que se le han concedido. La cuestión que entonces preocupa a Freud es determinar qué necesidad fundamenta el esfuerzo de la cultura por someter a una mayor ligazón, fundamento que parece asociarse a un factor perturbador.

Pues bien, el esquema ya esbozado por Freud y que ya atisbamos será completado rodeando críticamente el precepto que nos señala: "Ama a tu prójimo como a ti mismo". Como antes había ya señalado, este precepto constituye para Freud un reclamo ideal que puede ser contradicho en la medida en que el otro no siempre es digno de un merecimiento de tal tipo. Incluso, consecuente Freud con lo que ha venido afirmando, la actitud natural es más bien la hostilidad, ya que el escenario primordial ha sido constituido por la exigencia de satisfacer las necesidades inmediatas y obtener el mayor grado de ventaja en la economía libidinal. De tal modo a Freud le parecen más sensatas admoniciones del tipo: "Ama a tu prójimo tal como él te ama a ti", en la medida en que colocarían en un plano de mutua resistencia el encuentro con el otro. Se puede afirmar como clara prueba de la tesis freudiana el hecho de que tal precepto constituya precisamente un "mandamiento", en cuanto se nos ordena amar al otro precisamente porque no es la actitud natural. En palabras de Freud "justamente porque el prójimo no es digno de amor, sino tu enemigo, debes amarlo como a ti mismo"28.

\footnotetext{
${ }^{26}$ Ibíd., p. 101.

27 Ibíd., p. 103. Nótese que Freud señala la posible transformación evolutiva de una pulsión, en este caso las sexuales. ¿No complica este gesto todas las lecturas que pretenden reificar las pulsiones?

${ }^{28}$ S. Freud, El malestar en la cultura, op. cit., p. 107.
} 
Pues bien, tras este precepto, que se suma a toda una cadena prescriptiva en permanente mutación, lo que se esconde es un fragmento de realidad así desvelado: que el hombre no es un ser manso. Esta es la razón que impele a la cultura su gasto de energía. El trabajo y el amor no bastan para la ligazón, pues las pulsiones son más fuertes que los intereses racionales. De ahí que la cultura frene las exteriorizaciones pulsionales mediantes formaciones psíquicas reactivas. De ahí también su impulso hacia vínculos amorosos de meta inhibida y de ahí la limitación sexual y de ahí, finalmente, el precepto ideal en cuanto mandamiento, pues la naturaleza humana las contraría, como ya hemos esbozado.

Descritos de tal modo los lazos sociales, a Freud le parece injusto reprocharle a la cultura sus propósitos. A su vez, habría que destacar entonces dos cosas relativas a la identificación social siguiendo este marco teórico. Por una parte, Freud discierne las premisas socialistas como vanas ilusiones. Pues, efectivamente, aun cuando tengan reclamos culturales válidos y valiosos que logren vincular colectivamente a grupos humanos, no es menos cierto para Freud que la propiedad, el foco destacado por Marx para movilizar críticamente a las masas proletarias, se ofrece sólo como uno de los medios o instrumentos de agresión, pues aun suponiendo que se lograra una distribución más equitativa seguiría estando indeterminado el plexo de elementos que conjugan la satisfacción pulsional. Freud llega a señalar entonces que no debería menospreciarse el "narcisismo de las pequeñas diferencias", vale decir, la identificación comunitaria reconocida en oposición a otras culturas, ya que sus efectos de identificación sociocultural prueban ser muy valiosos ${ }^{29}$. De todos modos lo que se mantiene irreductible es el desequilibrio inexorable, siempre en movimiento, de la economía libidinal cundo se agencia con un conjunto de prácticas sociopolíticas.

Puesto que la cultura impone sacrificios no sólo a lo pulsional sino a la natural tendencia o inclinación a la agresividad se comprende entonces el malestar en la cultura. El primitivo no tenía limitación pulsional, pero no tenía seguridad. El hombre moderno se habría limitado un poco según Freud a cambio de una mayor seguridad, elementos que así constituyen una modulación en la economía libidinal. Es sin duda posible mejorar la estabilidad de esta economía pero un gran paso, el paso teórico aquí avanzado por Freud, es mostrar la irreductibilidad de esta inestabilidad. La vinculación total será imposible, pues nos constituimos de forma inexorable entre la ligadura y su dislocación, en la a-topía, y aquí se juega el enorme aporte de Freud.

El mismo Freud nos ofrecerá un apretado resumen de la doctrina de las pulsiones con revisiones a cosas no mencionadas acá y que convendría esquematizar, pues articula todos los pasos que hemos dado. Como señala, al principio se señaló que el hambre y el amor (Eros y Ananké) eran los pilares de la cultura. Con ello se distinguió entre pulsiones yoicas y pulsiones de objeto, siendo estas últimas las que reservarian el nombre de libido. Esta será la primera oposición, en la que se revelo el sadismo como componente de la libido. Aun cuando este esquema no

\footnotetext{
${ }^{29}$ Ibíd., p. 111. De forma brillante Freud aduce la importancia que tiene la identificación nacional cuando se establece en base al otro, a otros pueblos, cosa que vemos articulada como práctica común en los actuales sistemas democráticos cuando entran en crisis.
} 
deba calificarse de errado sin más, Freud sometió su esquema a una modulación en el momento en que la investigación pasó del análisis de lo reprimido a lo represor, vale decir de la libido al yo. En esta modulación el concepto freudiano decisivo es el de narcisismo y tiene como consecuencia dicha modulación, pues mostraría que el yo mismo es investido con libido y que constituye incluso su morada $^{30}$. Dimana así una libido narcisista que se vuelca hacia los objetos, como libido de objeto, aun cuando puede volver a constituirse como libido narcisista.

Así, el concepto de narcisismo fue clave para el análisis de las neurosis traumáticas pero, aun cuando para Freud no fuera descartable la explicación de la neurosis de transferencia como intentos del yo por defenderse de la sexualidad, con tal análisis el concepto de libido parecía vacilar, en la medida en que se había destacado ya que también las pulsiones yoicas eran libidinosas, cuestión que al parecer implicaba identificar la libido con la energía pulsional en general, cosa planteada, como se sabe, por Jung. Pero Freud señala que tenía la precaria certeza, algo así como una intuición, de que no podían ser todas las pulsiones de la misma clase.

El paso que daría más certeza, donde se recorren analíticamente los momentos acá descritos, será, como se sabe, Más allá del principio de placer, que ya hemos introducido. En dicho texto se revelaría junto a Eros (asociado ya acá a Ananké) una pulsión de muerte que impele al sujeto a volver a atrás, a la escena mítica primigenia, lo no simbolizable según Lacan. Es decir, junto a la tendencia de Eros de agruparse en unidades más grandes y asociarse para mantener la sustancia viva, habría otra pulsión que tendería a disolver esas unidades y asociaciones en búsqueda del estado inorgánico primitivo.

Si las exteriorizaciones de Eros a Freud parecían evidentes, se mostraba patente que Tánatos funcionaba al parecer muda al interior del sujeto en pos de su disolución. Sin embargo, más fructífera se ofrecía según Freud la idea de que de la pulsión de muerte se exteriorizaba en una parte que constituía el núcleo de la tendencia a agredir, puesta de tal modo al servicio de Eros, ya que un individuo que no exteriorizara la pulsión de muerte fácilmente se aniquilaría, caracterización que hace evidente la complementariedad de ambas pulsiones, como ya habíamos señalado, y patente de forma más nítida en fenómenos como el sadismo y el masoquismo 31 .

Freud señala las dificultades que entraña aceptar la pulsión de muerte, que reconoce él mismo resistir, pero señala a su vez que no se puede desconocer este carácter o rasgo ya que prueba de ello será siempre la existencia de crueldad no erótica. De forma sintética, dirá entonces Freud, en toda exteriorización pulsional participa la libido, pero no todo en ella es libido. Lo que se obtiene así es el reconocimiento de que la tendencia a la agresión es una disposición pulsional autónoma y es el mayor obstáculo que tiene a su haber la tarea cultural. La cultura es un proceso al servicio de Eros, que quiere unir al individuo en familias y a éstas en comunidades, pero la necesidad sola no logra la ligazón, el enlace de lo social.

${ }^{30}$ Cfr. S. Freud, El malestar en la cultura, op. cit., p. 114.
${ }^{31}$ Cfr. S. Freud, El malestar en la cultura, op. cit., p. 115

(c) EMUI Euro-Mediterranean University Institute | Universidad Complutense de Madrid | ISSN 1578-6730 Publicación asociada a la Revista Nomads. Mediterranean Perspectives | ISSN 1889-7231 
Es la pulsión de muerte que ya introducíamos la que frena sus intentos, cuestión que hará decir a Freud que la cultura no es otra cosa que la lucha, otra vez, entre Eros y Tánatos que ya estructuraba al devenir-sujeto del organismo de nuestro primer apartado.

\section{Génesis de la conciencia moral, historia y subjetivación política.}

Freud ha detallado ya, como hemos observado, mecanismos fundamentales de la cultura en su necesaria empresa de sofocación de las pulsiones. De todos modos le queda por barruntar el que considera más importante de todos. Se trata de la introyección de la agresión cultural en el yo ${ }^{32}$. Si partimos nuestra reflexión con el análisis de la economía libidinal en el organismo y su devenir-sujeto, bien puede considerarse este nuevo análisis como una continuación vinculante de esos motivos germinales con las características que hemos detallado de la cultura. No olvidemos que se trata de una estructura conjunta, cultura e individuo, a la que hemos ya añadido nuevas reflexiones sobre su génesis histórica.

Pues bien, se trata entonces de la agresión recogida por una parte del yo que, como sabemos, Freud denominará superyó. Señalado esto es fácil entender entonces el sentimiento de culpa como la tensión entre el superyó que se ha vuelto severo y el yo sometido a él, y que culminará en la exteriorización como necesidad de castigo. Ahora bien, como génesis de la culpa se señala comúnmente como raíz el obrar mal. No obstante, Freud desafía la hipótesis de una naturaleza que distinga lo bueno y lo malo y se queda con la hipótesis, convencional podríamos decir, de que lo malo es impuesto por los otros. Así, convendría precisar que malo es aquello por lo cual uno se ve amenazado con la pérdida de amor. En consecuencia, según Freud, eso caracterizado como malo debe ser evitado por la angustia frente a esa pérdida de amor.

De tal suerte, para Freud, en un primer grado, en vez de decir mala conciencia convendría decir angustia social. Cosa probada por lo demás al observar el obrar de los niños y de algunos adultos que proyectan en la comunidad un sustituto parental. Sobrevendrá un cambio de este esquema sólo con la formación, en lo que constituye un segundo grado, del superyó, y es recién en este momento en que podemos hablar de "conciencia moral" ${ }^{33}$. Tenemos así que en un primer grado no hay en rigor la conciencia de culpa sino angustia social y luego, solamente luego, surge la conciencia moral y el sentimiento de culpa.

Hay que detenerse acá para atravesar lo que puede constituir una grave contradicción, aunque sólo aparente. Hemos detallado un doble origen del sentimiento de culpa. Por una parte la angustia frente a la autoridad (los otros), instancia que impele al individuo a la renuncia pulsional. Por otra parte la angustia frente al superyó, que instala también el castigo en la medida en que ya no sólo la ejecución de lo prohibido sino también el deseo de lo prohibido puede ser

\footnotetext{
32 Cfr. S. Freud, El porvenir de una ilusión, op. cit., p. 11. Ahí se señala que esta introyección constituye el núcleo del progreso humano.

33 Cfr. S. Freud, El malestar en la cultura, op. cit., pp. 121-122.
} 
evaluado. La severidad del superyó será así entonces el relevo y sustitución de la autoridad externa.

Si vinculamos la renuncia pulsional con la conciencia moral obtenemos lo siguiente: En un primer momento la renuncia pulsional es la consecuencia de la angustia a la autoridad externa o angustia social, como la llama Freud. Efectuada esa renuncia no debería quedar rastro de culpabilidad y la desdicha debería ser superada. Pues bien, muy distinto será lo que ocurre con la autoridad interiorizada. En efecto, en dicha instancia la renuncia pulsional ya no vale, ya que el deseo persiste y no puede ser escondido al superyó. Con lo cual dimana un sentimiento de culpa permanente que imposibilita atravesar plenamente la dicha de la mera renuncia pulsional.

El problema sería el siguiente. En un comienzo la conciencia moral (o angustia social) es la causa de la renuncia pulsional. Luego, no obstante, esta relación se invierte y es la renuncia pulsional la causa de la conciencia moral que, ya generada, pedirá vigilantemente más y más renuncias pulsionales. Con todo, en rigor debe afirmarse, paradójicamente en cuanto de común pensamos más bien lo contrario, que es la renuncia pulsional la génesis de la conciencia moral ${ }^{34}$. En síntesis cabe afirmar que la conciencia moral surge por la sofocación de fragmentos de agresión siendo la relación establecida entre el yo y el superyó el retorno, desfigurado por el deseo, de un yo, todavía no dividido, y el objeto exterior al cual se teme ${ }^{35}$. Ha quedado así establecida por Freud la ligadura entre renuncia pulsional y conciencia moral.

Freud señala que la observación directa permite comprobar esto, pues la violencia vengativa del hijo se establece respecto a la demanda de violencia que espera del castigo paterno. Aunque señala no obstante que se puede objetar que una educación blanda sin duda puede generar en ciertos niños conciencias morales muy severas. A pesar de esto, si bien el niño no refleja absolutamente ese nivel de violencia paterna, es lícito no desligar esa relación, aun cuando intervengan factores ambientales decisivos. En un pasaje muy sugerente, Freud señala que en el niño bien puede responder la génesis moral a un arquetipo filogenético, en la medida en que el primer padre, el padre de la horda que mencionamos, si era temible y severo ${ }^{36}$. Quedan así ligadas inexorablemente ontogénesis y filogénesis, y se aprecia así no un soslayamiento de las condiciones históricas sino, muy por el contrario, su permanente atención y vigilancia crítica. Pues parece evidente con lo dicho para Freud que el sentimiento de culpa no desciende sino del complejo de Edipo y del parricidio primordial, y que estructura el devenir evolutivo del sujeto político, aun cuando se trate de una hipótesis especulativa.

\footnotetext{
${ }^{34}$ Cfr. S. Freud, El porvenir de una ilusión, op. cit., cap. 2. Se señala acá de forma análoga que los rendimientos culturales producen los ideales de la comunidad y no al revés.

${ }^{35}$ Cfr. S. Freud, El malestar en la cultura, op. cit., p. 125.

${ }^{36}$ Cfr. S. Freud, El porvenir de una ilusión, op. cit., cap. 2. En este pasaje Freud menciona de forma muy sugerente que nivel moral significa lo mismo que aceptación de los preceptos culturales admitidos hegemónicamente. Las consecuencias filosóficas inmediatas son evidentes, ya que implica el renunciamiento de una deducción transparente de acuerdo a la autoposición del sujeto de la norma moral absoluta como en Kant. Lacan desde otra perspectiva volverá a mencionar este empuje antifichteano en Freud en La cosa freudiana...
} 
De todos modos surgiría acá una dificultad que Freud precisa. Pues con el parricidio primordial no se sofocó una agresión sino que se ejecutó, cosa que contradice la primera hipótesis de la sofocación, dando a entender que da lo mismo matar o no al padre. Pero no hay tal contradicción. El parricidio lo que genera es más bien arrepentimiento, con lo cual hay que suponer previamente ya una conciencia moral germinal y un sentimiento de culpa, que queda ahí establecido y claramente identificado por la ambivalencia de sentimientos hacia el padre, ya que los hijos tanto odiaban como amaban al padre primordial. Perpetrado el acto mediante la agresión quedó la culpa producto del amor que se le sentía. Efectivamente, da lo mismo matar o no al padre, ya que el sentimiento de culpa surgirá inexorablemente, pues es producto de esa ambivalencia que es la lucha eterna, nuevamente, entre Eros y Tánatos. Queda así resuelto ese pasaje. Lo destacable es que el complejo de Edipo es el núcleo familiar que, al ampliarse en comunidades más y más grandes, se prolonga también, y en formas dependientes también del pasado, de la historia, plexo que en su conjunto tiende con ello a ampliar más todavía el sentimiento de culpa, asentado filogenéticamente ${ }^{37}$.

Aclarando un poco más las cosas podemos señalar siguiendo a Freud que es la institución del superyó quien modifica el esquema. El sentimiento de culpa es en un caso, en su origen histórico, consecuencia de una efectiva agresión y, en otro, consecuencia de la inclinación a la agresión inhibida. Antes por lo tanto se puede pensar que el sentimiento de culpa coincidía con arrepentimiento, cuestión que cambia con la institución del superyó.

Vemos así que la égida freudiana es mostrar cómo el sentimiento de culpa es el refuerzo de la cultura, generada también dicotómicamente por amor, para lograr constituirse plenamente. El sentimiento de culpa dimana en Freud el problema más gravitante de la cultura, pues su progreso sólo se sustenta al precio de un déficit de dicha pagada mediante la elevación del sentimiento de culpa que, siguiendo lo que señalábamos, puede entenderse como una variedad tópica de la angustia que, en sus fases tardías, culmina en angustia frente al superyó y en la conciencia moral. El sentimiento de culpa es lo mismo que la severidad de la conciencia moral: la apreciación entre las aspiraciones y los reclamos del superyó ${ }^{38}$. Aun así, en rigor, como dijimos, no debiera hablarse de conciencia moral antes de la institución del superyó. La conciencia de culpa sí es anterior al superyó o conciencia moral. Mejor conviene distinguir entre dos estratos del sentimiento de culpa: angustia frente a la autoridad externa y angustia ante la interna.

37 Cfr. S. Freud, El malestar en la cultura, op. cit., p. 128.

${ }^{38}$ Freud señala que la prueba evidente del carácter gravitante de la culpa en la cultura es el estatuto que le otorga la religión, cuestión que admite no haber precisado en El porvenir de una ilusión, que intentaba más bien explicar el fenómenos como exorcismo de las fuerzas nefastas de la naturaleza. De todos modos, esa naturaleza había sido investida con rasgos paternales de acuerdo a un componente filogenético, de forma que ambas concepciones se acercan, como lo expresa no obstante Freud en el cap. 4 de El porvenir de una ilusión refiriéndose a los hallazgos desplegados en Tótem y tabú. 
Que no quede claro que es esa angustia como sentimiento de culpa lo que produce el malestar en la cultura lo prueba el que muchas veces permanece oculta o muda, aunque otras, como en ciertas neurosis, aflora de forma muy patente. Por último, cabría destacar que Freud reservará el sentimiento de culpa para la inhibición solamente de pulsiones agresivas y no para las libidinales. Cuestión que le permite establecer que en las neurosis los componentes libidinosos se mudan en síntomas y los agresivos en sentimiento de culpa.

Lo que es importante destacar en lo que hemos avanzado es que tanto el proceso cultural como el individual, las dos máquinas, componen el carácter universal de la vida: la lucha entre Eros y Tánatos. De todas maneras, aun cuando la cultura no sea más que un orden de abstracción más elevado que la ontogénesis sí cabe destacar una diferencia. Si en el desarrollo individual hemos atisbado una duplicidad pulsional, es evidente que siempre en el individuo prevalecerá la dicha como meta, y con ello el egoísmo. Con la cultura pasa todo lo contrario para Freud, ya que bien podría ella renunciar a la dicha en su empeño por formar unidades más amplias (su meta) cada vez mayores conjuntos de homogenización.

Freud destacará nuevas analogías entre ambos procesos, entre las que cabe destacar de forma prioritaria la instalación en la comunidad misma de un superyó. Serán para Freud los preceptos de este superyó (considerando siempre su asiento en la historia) la conformación de la ética, que habrá de concebirse en consecuencia como terapia contra los impulsos ya analizados ${ }^{39}$. Lo que el análisis revela entonces es la necesidad de debilitar muchas veces las severas exigencias del superyó. Considerando esto, bien podría verse acá el paso tentativo para un análisis de las patologías sociales que implicaría analizar la severidad de los preceptos éticos epocales, es decir, un diagnóstico del presente o una ontología del presente. De todos modos, considerando que jamás se podrá renunciar a estas pulsiones, nadie puede prever el desenlace, señala Freud, que tendría el enlace sociopolítico así mentado.

\section{Conclusión: Heteronomía, des-enlace, homogenización}

La pulsión de muerte que analizamos al inicio se ve entonces relevada en los textos sociopolíticos por la figura de la indiferencia, es decir, aquel estado primordial estructurado bajo el narcisismo primordial al cual el sujeto siempre querrá volver, y que se configura también, como vimos, en libido de objeto. El quiebre o ruptura que lo hace instalarse en el plexo social es precisamente eso, un corte o ruptura, que acontece, de acuerdo a lo señalado, ya sea por estímulos internos, como el hambre (Ananké), ya sea por externos, que constituirán a la postre el reforzamiento de la cultura. Entendamos entonces que el trabajo de subjetivación anímica es un pasaje de la indiferencia inicial a la diferencia, de acuerdo al poder de lo simbólico, de la simbolización, según Lacan.

\footnotetext{
${ }^{39}$ Es destacable que Freud aúna la posición kelseniana del positivismo jurídico en general, con otras disciplinas contrarias, entre las que se incluye Max Weber. La moral sí obedece a la interiorización de la normativa positiva, pero descansa inexorablemente en el fondo oscuro del asesinato primordial.
} 
Una primera consecuencia importante es que de no escuchar esta otra escena que nos señala Freud, posiblemente se genere una cultura que, en sus intentos de resistir a la des-ligazón, al des-enlace comunitario irreductible que con tanto énfasis destaca Freud, provoque una homogenización absoluta o reificación total, aunque esa reificación no puede ser detallada transparentemente, como intentará Marcuse, para encontrar por detrás de los lazos todavía un sujeto social, y a la vez pleno, en la medida en que el corte simbólico se establece en una relación económica, detallada por Freud en una lógica complementaria. No son descripciones que soslayen la historia, sino análisis que podrían entenderse como meta-estructurales, marcados por la fidelidad a la historia y sus determinaciones. Freud trae con ello otro tipo de verdad. Pues si Kant asoció la verdad a la aplicación de categorías, y Hegel la articuló en el despliegue del concepto en su devenir (Werden) Freud marcaría el desgarro abisal de estas doctrinas, que descansan en la ratio, en el des-pliegue de lo racional, de forma evidente en Hegel.

Esta otra escena está asentada en la historia o, como Freud precisa siempre, es el despliegue de una verdad histórica, pero ya no como en Hegel del devenir racional del concepto, sino de su otro, de su inconsciente. Si Freud combate, como vimos, la descripción sociológica y nominalista del totemismo es precisamente para señalar su desprendimiento de análisis basados en la ratio. Al señalar que en el Edipo tendría su basamento el totemismo y la exogamia Freud intenta justificar toda la ontogénesis desde la filogénesis y de ahí la vuelta que opera en El malestar de la cultura al final de su recorrido, ya que del análisis de la subjetividad desdichada se retoma luego el análisis de ella tras el material histórico que ha resultado determinante.

Como vimos, luego del crimen primordial la opción habría sido para la comunidad de hermanos volverse Uno o reivindicar lo Uno. Ahora bien, con la culpa la simbolización no es completa respecto al banquete, pues quedaría algo del padre no simbolizable del todo y que dejaría precisamente como residuo la culpa. Freud encuentra acá la idea de dios, pues se trataría de un producto secundario respecto al asesinato primordial. El resto del padre es lo que se repite en toda formación psicopatológica, y no solamente individual, ya que la religión es una neurosis colectiva para Freud, sustitutiva del padre. Este sería su fundamento histórico que revela las categorías fundamentales ( $\mathrm{y}$, como vemos, fundantes).

La lógica freudiana es así la lógica que transita entre la indiferencia (propia del narcisismo) y la diferencia, y no la lógica individuo-cultura que marcó los análisis dicotómicos freudomarxistas. Si seguimos a Lacan, entenderemos, bajo esta égida, cómo lo Real funda lo simbólico, desde un punto insimbolizable. Y que tanto lo imaginario como lo simbólico trabajan en pos de ese punto ciego. La metáfora del nombre del padre, germinal con Freud, es un proceso inaugural, con el cual se accede a lo simbólico. Estructura un proceso de división psíquica (Spaltung) como un mecanismo irreversible en el sujeto, formando una división estructural.

Pues bien, ¿cuál es el principio que gobierna esta división? El principio para Lacan es la categoría de significante, la que posibilita el advenimiento del sujeto. El significante hace advenir al sujeto a una estructura de división o, en otras 
palabras, el sujeto está escindido por el lenguaje: de ahí que se afirme que el inconsciente está sujeto. Lacan destaca la Spaltung freudiana pues ve ahí el proceso característico para la constitución del sujeto, en tanto constituye el modo psíquico de advenimiento a la cultura, ya que la Spaltung hace ver el estado de sujetamiento respecto a un orden simbólico determinante. Si hay una causa (aitía) del sujeto es así la causa del orden significante, por lo tanto de división o desligazón o des-enlace, que ya tanto preocupa a Freud y que nos exhorta a mantener presente.

El inconsciente da lugar a una trama, a una concatenación significante revelando otra escena que no respeta la linealidad del decir. De ahí que Lacan afirme que el inconsciente es el lenguaje del Otro. Lo fundamental, como señala Lacan, es que: 'Para que reconozcamos a ese 'yo' (je) porque habla, tal vez no era sobre el 'yo' (je) sobre quien había que lanzarse, sino en las aristas del habla donde debíamos detenernos" $"$. Esta sería la escena mostrada por Freud.

La división que opera el orden significante en el sujeto instala otra propiedad fundamental para Lacan que es la alienación. Se trata de una alienación del hombre al lenguaje, que se encuentra alienado respecto al orden significante que lo produce. Este efecto de escisión tiene como consecuencia que el sujeto no figure en su propio discurso, y sólo se reencuentre representado en lo simbólico, y con ello que el sujeto se vea eclipsado en su identidad.

Con la Spaltung nos conducimos así al sujeto lacaniano barrado, que mostrará la oposición entre dos categorías fundamentales: Por una parte, el sujeto de la enunciación, donde encontramos el sujeto del inconsciente, que dice la verdad pero a medias (lo dicho). Por otra parte, el sujeto del enunciado, o simplemente el enunciado (lo proposicional). De ahí que la técnica analítica consista, como vimos en la cita, en sancionar lo dicho en el decir. Pues la verdad adviene, para Lacan y Freud, como se sabe, en el fracaso del decir. Esta otra verdad revelada, ontofilogenética, queda muy bien expresada cuando Lacan señala: "(...) el sujeto al que se califica (significativamente) de paciente, el cual no es el sujeto estrictamente implicado por su demanda, sino más bien el producto que se desearía determinado por ella" ${ }^{41}$.

Una última consideración. En El porvenir de una ilusión Freud señala: "Así, se recibe la impresión de que la cultura es algo impuesto a una mayoría recalcitrante por una minoría que ha sabido apropiarse de los medios de poder y compulsión"42. Uno podría pensar que esta frase fue pronunciada por Foucault, más aún considerando que Freud establece la tentativa expuesta en El porvenir de una ilusión como una arqueología de los cimientos de la civilización ${ }^{43}$. No obstante, como hemos tratado de señalar, Freud, con todas las limitaciones epocales propias de su tiempo, ha podido instalar otro tipo de heteronomía desde el momento en que se reconoce otro vector histórico aparte de la racionalidad. Para Freud hay que pensar más bien en la necesidad de la coerción, pues todos los

40 J. Lacan, La cosa freudiana..., op. cit., p. 396.

41 J. Lacan, "Del sujeto por fin cuestionado", en: Escritos 1, op. cit., p. 220.

42 Cfr. S. Freud, El porvenir de una ilusión, op. cit., p. 6.

43 Ibíd., p. 34-35. 
hombres integran tendencias destructivas que hemos desvelado, y que constituirían la plataforma para las tentativas lacanianas.

Lo interesante a su vez es que Freud desplaza la cultura como mera distribución de bienes materiales al campo de lo anímico (motivo destacado por Lacan en El sujeto por fin cuestionado) con lo que la heteronomía marxista sería también reconducida a nuevos pilares. Sin desconocer estas tendencias, la modulación económica que inserta la cultura debe entenderse en el plexo que vincula la denegación (el hecho de que un instinto no pueda ser satisfecho), la prohibición (la institución que marca la interdicción, y que articulamos con la cita de B. Ogilvie) y la privación (estado que la prohibición trae consigo) ${ }^{44}$.

Habíamos señalado cómo en El porvenir de una ilusión Freud vincula el nivel moral con la aceptación de los preceptos morales. Atendamos a su vez al hecho de que no cese de mencionar cómo una cultura retrógrada encomienda a los dioses velar por los preceptos éticos, a los cuales se atribuye un valor divino, situándolos por encima de la sociedad humana. Con la crítica a este tipo de cultura retrógrada, en la medida en que crea representaciones de defensa extraídas del material de su infancia, y asentada en su base filogenética, ¿no podemos decir que ganamos con ello cierto aspecto pragmático en Freud? ¿No podríamos ver acá una plataforma para pensar de otro modo los sistemas morales contemporáneos que creen ver en su aspecto postconvencional una verdadera crítica a la autonomía moderna? Efectivamente, con Freud parecemos ganar una suerte de pragmatismo, quizá cercano a Nietzsche, y sobre todo porque, a diferencia de pragmatismos actuales, el sistema de Freud retoma el conjunto basal de las hegemonías contemporáneas, pues, ¿no encuentra graves daños con Freud una teoría que afirme que si bien los valores morales son contingentes estos se crean "conversacionalmente"? ¿No se soslaya un hecho primordial acá? Este no reconocimiento parece ser la excentricidad radical del sujeto que inauguro Freud, que disloca como vimos toda edificación social transparente ${ }^{45}$.

Efectivamente, una lectura parcial de Nietzsche podría ser análoga con Freud en muchos motivos, sobre todo en consideración del reconocimiento necesario de la coerción que tanto preocupaba al martillo de Rocken. Si era aceptable un nivel de fuerzas en Nietzsche que vigilase la anarquía de las pasiones, Freud llega incluso, en un juego ficcional en El porvenir de una ilusión, a ver la posibilidad de una salida social en la religión que tanto combate. Pues si la religión parece domesticar a los hombres ¿para qué entonces habriamos de cambiarlos? No obstante, el dios logos permite decir a Freud que la razón que se intenta mostrar a través de su genealogía conduce siempre al alejamiento de las falsas servidumbres. $Y$ de esto se trata al fin con el des-enlace analizado por Freud.

Como Lacan señalaba, si bien el sujeto del psicoanálisis viene a perturbar el orden científico, sólo lo hace para allanar su camino ${ }^{46}$.

\footnotetext{
lbíd., p. 10.

Cfr. J. Lacan, "La cosa freudiana...", op. cit., p. 400.

Cfr. J. Lacan, "Del sujeto por fin cuestionado", op. cit., pp. 224-225.
} 


\section{Bibliografía Fundamental:}

FREUD, S.: Proyecto de psicología, Bs. As.: Amorrortu Editores (AE), 2003, T. 1.

-. Más allá del principio de placer, AE, T. 18.

-. Tótem y tabú, T. 13.

-. Psicología de las masas y análisis del yo, T. 18.

-. El malestar en la cultura, T. 21.

-. El porvenir de una ilusión, T. 21.

LACAN, L.: "La cosa freudiana o el sentido del retorno a Freud en psicoanálisis" en: Escritos 1, México: Siglo XXI, 1990.

-. "Subversión del sujeto y dialéctica del deseo en el inconsciente freudiano" en: Escritos 2, México: Siglo XXI, 1990.

-. "Del sujeto por fin cuestionado" en: Escritos 1.

-. "La instancia de la letra en el inconsciente o la razón desde Freud" en: Escritos 1.

ZIZEK, S.: El espinoso sujeto, Argentina: Paidós, 2005. 